\title{
Body composition as a predictor of chemotherapy toxicity in patients with metastatic prostate cancer treated with docetaxel
}

\author{
S. J. Cushen ${ }^{1}$, D. G. Power $^{2}$, R. McDermot ${ }^{3}$, K. O’Sullivan ${ }^{4}$, P. Maceneaney ${ }^{5}$, L. Daly ${ }^{1}$ and \\ A. M. Ryan ${ }^{1}$ \\ ${ }^{1}$ Dept Food \& Nutritional Sciences, University College Cork, Republic of Ireland, ${ }^{2}$ Dept Medical Oncology, Mercy \& \\ Cork University Hospitals, Cork, Republic of Ireland, ${ }^{3}$ Dept Statistics, University College Cork, Republic of Ireland, \\ ${ }^{4}$ Dept Medical Oncology, St. Vincents University Hospital, Dublin, Republic of Ireland and ${ }^{5}$ Dept Radiology, Mercy \\ University Hospital, Cork, Republic of Ireland
}

Body composition is an important prognostic factor in cancer and evidence supporting a strong link between low skeletal muscle mass (sarcopenia) and chemotherapy toxicity is increasing ${ }^{(1)}$. Docetaxel is standard first line treatment for castrate resistant prostate cancer $(\mathrm{CRPC})^{(2)}$. The aim of this study was to correlate body composition (by computed tomography (CT)) with toxicity to docetaxel in CRPC.

Patients with CRPC who received docetaxel between 2008-2013 were included. Correlations between patient characteristics, body composition and toxicity to chemotherapy were analyzed. Skeletal muscle was measured by CT and sarcopenia was defined using published cut offs ${ }^{(3)}$. Toxicity was assessed using Common Terminology Criteria for Adverse Effects v4.0.

63 pts, mean age $69 \mathrm{y}$ (SD 8), were included. In total $76 \%$ of pts were overweight or obese (BMI $\left.>25 \mathrm{~kg} / \mathrm{m}^{2}\right)$. Sarcopenia was present in $71.4 \%(\mathrm{n}=45)$ and of these $31(68.8 \%)$ were both sarcopenic and overweight or obese. Sarcopenic patients had a lower BMI $(26.6$ vs. $\left.30.9 \mathrm{~kg} / \mathrm{m}^{2}, \mathrm{p}<0.001\right)$ compared to non-sarcopenic pts. Grade $3-4$ toxicity was seen in $23 \%(\mathrm{n}=14)$ during the first 3 cycles of treatment, the most common being peripheral neuropathy $(40 \%)$, neurosensory $(36 \%)$ and anaemia $(33 \%)$. Neutropenia and neurosensory toxicities were more prevalent in sarcopenic patients $(\mathrm{p}<0 \cdot 05)$. Patients with a skeletal muscle index $(\mathrm{SMI})<25^{\text {th }}$ centile $(45$ $\mathrm{cm}^{2} / \mathrm{m}^{2}$ ) received less treatment compared to patients with $\mathrm{SMI}>75^{\text {th }}$ centile (88 days vs 153 days, $\left.\mathrm{p}=0 \cdot 055\right)$. Analysing the drug dose according to $\mathrm{SMI}\left(\mathrm{cm}^{2} / \mathrm{m}^{2}\right), 32 \%$ of patients receiving a dose $>75^{\text {th }}$ centile $(1.98 \mathrm{mg} / \mathrm{SMI})$ experienced neutropenia in the first 3 cycles vs $0 \%$ receiving a dose $<25^{\text {th }}$ centile $(1.347 \mathrm{mg} / \mathrm{SMI} ; \mathrm{p}<0.05)$. High BMI was significantly associated with better survival, BMI $\geqslant 25$ $\mathrm{kg} / \mathrm{m}^{2}: 586$ days vs 418 days for BMI $<25 \mathrm{~kg} / \mathrm{m}^{2}, \mathrm{p}<0 \cdot 05$. CRP was also prognostically significant, with values $>75^{\text {th }}$ centile $(133 \mathrm{mg} /$ dl) having a shorter survival compared to pts with $C R P<75^{\text {th }}$ centile $(150$ vs. 661 days; $p<0 \cdot 05)$.

Sarcopenia is highly prevalent in pts with CRPC receiving docetaxel but is masked by excessive adiposity. Very low skeletal muscle mass is associated with less treatment days and increased neurological and haematological toxicities. High BMI is associated with longer survival.

1. Antoun S, Borget I \& Lanoy E (2013) Curr Opin Support Palliat Care 7, 383-389.

2. Saad F \& Hotte SJ (2010) Can Urol Assoc J 4, 380-384.

3. Mourtzakis M, Prado CM, Lieffers JR et al. (2008) Appl Physiol Nutr Metab 33, 997-1006. 